\title{
2-DE-MS based proteomic investigation of dairy cows with footrot
}

\author{
Jiasan Zheng ${ }^{1,2}$, Shi Shu ${ }^{2}$, Cheng $\mathrm{Xia}^{2,3}$, Chuang $\mathrm{Xu}^{2}$, \\ Hongyou Zhang ${ }^{2}$, Hongbin Wang ${ }^{1}$ \\ ${ }^{1}$ College of Veterinary Medicine, ${ }^{3}$ Synergetic Innovation Center of Food Safety and Nutrition, \\ Northeast Agricultural University, Harbin 150030, People's Republic of China \\ ${ }^{2}$ College of Animal Science and Veterinary Medicine, \\ Heilongjiang Bayi Agricultural University Daqing High-tech Industrial Development Zone, \\ Daqing 163319, People's Republic of China \\ hbwang@neau.edu.cn.
}

Received: September 28, 2015 Accepted: February 19, 2016

\begin{abstract}
Introduction: The differentially expressed proteins between healthy cows and those with footrot were identified to explore changes in protein profiles associated with the disease. Material and Methods: Out of 36 cows selected for the experiment, 18 footrot-affected cows were included in the treatment group (group T) and 18 unaffected cows were included in the control group (group C). Plasma samples from groups $\mathrm{T}$ and $\mathrm{C}$ were subjected to two-dimensional electrophoresis analysis and differentially expressed proteins were identified by matrix-assisted laser desorption/ionisation tandem time-of-flight mass spectrometry. Bioinformatics, including gene ontology analysis and pathway analysis, was used for analysing all proteins. Results: Out of 63 spots identified by 2DE, 33 were selected for mass spectrum analysis, which identified 11 differentially expressed proteins in 26 spots. Footrot led to changes in profiles in plasma proteins that were classified to the pathway of inflammatory response, complement, and blood coagulation, among others. Conclusion: This study provides evidence of the defence mechanisms of cows with footrot to explore strategies for treatment.
\end{abstract}

Keywords: dairy cows, 2-DE-MS, proteomic, footrot.

\section{Introduction}

Two species of anaerobic bacteria, Fusobacterium necrophorum and Bacteroides melaninogenicus, are known causative agents of footrot, a highly transmittable disease; they are usually present in the rumen and faeces of dairy cows, and are often found within the environment of dairy farms (23). The predominant clinical symptom of this painful and contagious disease in cattle is lameness, which is characterised by the presence of swelling of the foot, marked cracking and sloughing of interdigital skin, puffiness of the coronary band, and purulence. In dairy cows it is caused by the development of infection between the two toes of the affected animal (20). In the late stage, footrot can be diagnosed by the presence of reddening of the skin and a distinct foul smell. This disease is treated by antibiotic therapy and infected cattle are quarantined to prevent spread of the infection to the rest of the herd (7). Since there is a high incidence of footrot among dairy cows in England, the USA, and China, it is important to develop effective treatment strategies. However, such efforts have been complicated by the complex aetiology of the disease, which causes extensive damage to the cattle $(4,6,17$, 18). Hence, footrot is a severe disease that should be diagnosed during the early stage of infection, although the exact pathogenesis of footrot remains unclear.

Comparative proteomic analysis, a powerful and efficient tool for the systematic investigation of protein profiles from biological samples, integrates with two analytical techniques for protein profile analysis: two-dimensional electrophoresis (2-DE), and mass spectrometry (MS) (12, 19). However, this technique is rarely used for identification of pathogens associated with lameness of dairy cows, especially in plasma obtained from animals with footrot. 
In the present study, 2-DE and matrix-assisted laser desorption/ionisation tandem time-of-flight mass spectrometry (MALDI-TOF/TOF/MS) were used to identify proteins differentially expressed in plasma between healthy dairy cows and those with footrot. The aim of this investigation was to identify differentially expressed plasma proteins in dairy cows with footrot as possible biomarkers for early diagnosis and treatment. In addition, the research results may also provide information to further elucidate the pathogenesis of footrot in dairy cows.

\section{Material and Methods}

Animals. Eighteen plasma samples from diseased cattle following an outbreak of footrot were collected from a Holstein dairy herd located in the Harbin area of Heilongjiang Province, northeast China. These dairy cows were lactating and at the same age (4 years old) and parity, with similar milk yield ( $>6$ tonnes $/ 305 \mathrm{~d}$ ). Blood samples (about $10 \mathrm{~mL}$ ) were collected from the caudal vein into blood collection tubes containing anticoagulant. The infected cows showed obvious swelling of the skin between the toes of the hoof, which is a characteristic clinical sign of footrot. In hoof swabs of footrot-affected cows, the presence of the lktA gene of $F$. necrophorum was confirmed by PCR analysis. After centrifugation at $3000 \times \mathrm{g}$ for $8 \mathrm{~min}$ at $4^{\circ} \mathrm{C}$, the resulting plasma specimens were centrifuged for the second time at $12000 \times g$ for $5 \mathrm{~min}$ at $4^{\circ} \mathrm{C}$. Every six individual samples from the diseased cattle were combined into one hybrid sample. At the same time, blood samples from 18 unaffected cattle in the affected dairy herd were also combined into three hybrid samples. Finally, a total six hybrid samples were stored at $-80^{\circ} \mathrm{C}$ for $2-\mathrm{DE}$.

Protein extraction. The plasma samples were centrifuged $(15 \mathrm{~min}, 15000 \times \mathrm{g})$ and the supernatant of each sample was collected. Albumin and immunoglobulin $\mathrm{G}$ ( $\mathrm{IgG}$ ) of the plasma were removed from the sample using the ProteoExtract ${ }^{\circledR}$ Albumin/IgG Removal Kit (Merck KGaA, Germany). The protein solution was centrifuged (15 min, $15000 \times g)$. Next, cold acetone $(5: 1, \mathrm{v} / \mathrm{v})$ was added to each sample, which was then incubated for $1 \mathrm{~h}$. Afterward, the samples were centrifuged $(15 \mathrm{~min}, 12000 \times \mathrm{g})$ and the protein deposits were collected and dried. The dried deposits were dissolved in lysis solution containing $9 \mathrm{M}$ urea, 4\% 3-((3-cholamidopropyl) dimethylammonio)-1-propanesulfonate (w/v, CHAPS), $1 \%$ dithiothreitol (w/v, DTT), $1 \%$ isopropylideneguanosine (IPG) buffer (v/v) (pH 3-10, GE Healthcare Bio-Science, Little Chalfont, UK). Subsequently, the solution was centrifuged $(15 \mathrm{~min}, 15000 \times \mathrm{g})$ and the protein concentration was determined using the Bradford method (2).

2-DE and data analysis. Albumin and $\mathrm{IgG}$ of the plasma were removed from the sample using the
ProteoExtract ${ }^{\circledR}$ Albumin/IgG Removal Kit (Merck $\mathrm{KGaA}$ ). Next, the proteins of the samples were extracted. Samples containing $200 \mu \mathrm{g}$ protein were brought to a total volume of $450 \mu \mathrm{L}$ by the addition of fresh rehydration buffer ( $9 \mathrm{M}$ urea, 1\% IPG buffer, $4 \%$ DTT, 1\% CHAPS, and a trace amount of bromophenol blue) and loaded on an IPG strip (pH 3-10, $24 \mathrm{~cm}$, nonlinear, GE Healthcare Life Sciences, USA). Isoelectric focusing was performed using an IPGphor system (GE Healthcare Life Sciences) with the following protocol: $20^{\circ} \mathrm{C}$; $50 \mu \mathrm{A}$ per strip; voltage: $50 \mathrm{~V}$ for $12 \mathrm{~h}$ (step), $500 \mathrm{~V}$ for $1 \mathrm{~h}$ (step), $1000 \mathrm{~V}$ for $1 \mathrm{~h}$ (step), $10000 \mathrm{~V}$ for $1 \mathrm{~h}$ (gradient), and $10000 \mathrm{~V}$ for $11 \mathrm{~h}$ (step). The strips were subsequently incubated in equilibration buffer (I) (6 M urea, 1\% DTT, 2\% sodium dodecyl sulphate (SDS), 30\% glycerol, $50 \mathrm{mM}$ Tris- $\mathrm{HCl}$, and bromophenol blue), and then the strips were removed and incubated in equilibration buffer (II) (6 M urea, 2\% SDS, 30\% glycerol, $2.5 \%$ iodoacetamide (w/v), $50 \mathrm{mM}$ Tris- $\mathrm{HCl}$ ( $\mathrm{pH} \mathrm{8.8),} \mathrm{and} \mathrm{bromophenol} \mathrm{blue).} \mathrm{After} \mathrm{that,}$ the IPG strips were loaded on a $12 \%(\mathrm{w} / \mathrm{v})$ gel for SDSpolyacrylamide gel electrophoresis (PAGE, 12\% (w/v) using the Ettan DALTsix Electrophoresis System (GE Healthcare Life Sciences). The gels were run at $100 \mathrm{~V}$ for $1 \mathrm{~h}$ and maintained at $200 \mathrm{~V}$ for $6-8 \mathrm{~h}$. Then, the gel was visualised by silver staining according to Shevchenko's protocol (16) and scanned with Image Scanner software (GE Healthcare Life Sciences). The gel images were processed according to three steps (spot detection, volumetric quantification, and matching) by PDQuest 2-D Analysis Software version 8.0 (Bio-Rad Laboratories, Inc., USA). The differences in protein content were calculated as fold ratio. The differentially expressed protein spots were selected (a threshold of $\mathrm{P} \leq 0.05$ and fold change $\geq 1.5$ or $\leq 0.67$ ) for further analysis.

Protein identification by MALDI-TOF/TOF/MS and database search. Gel spots were excised and destined for protein identification. Samples were resuspended in trifluoroacetic acid (TFA, $5 \mu \mathrm{L}, 0.1 \%$ ) and mixed by a matrix composed of a saturated solution of $\alpha$-cyano-4-hydroxy-trans-cinnamic acid in $50 \%$ acetonitrile/ $0.1 \%$ TFA (1:1). Peptide MS and MS/MS were performed using an ABI 5800 MALDITOF/TOF Plus mass spectrometer (Applied Biosystems, USA). The data were obtained with a CalMix5 standard to calibrate the instrument (ABI5800 Calibration Mixture; Applied Biosystems). Then, the MS and MS/MS data were integrated and processed with GPS Explorer V3.6 software (Applied Biosystems) with default parameters. According to the MS and MS/MS spectra, these proteins were identified based on a confidence interval of $\leq 95 \%$ of the scores retrieved from the MASCOT V2.3 search engine (Matrix Science Ltd., UK).

Clustering analysis. The relative quantification results were analysed using MultiExperiment Viewer software (MeV, V4.8.1) and compared to the 2-DE results. 
Bioinformatic analysis. Gene ontology (GO) analysis by the DAVID database (https://david. ncifcrf.gov) and pathway analysis with the Kyoto Encyclopedia of Genes and Genomes (KEGG) database (http://www.genome.jp/kegg/pathway.html) were carried out to investigate differentially expressed proteins.

Western blotting. Equal amounts of plasma proteins were resolved in 10\% SDS-PAGE gels and then transferred to polyvinylidene fluoride membranes (EMD Millipore, USA). After incubation in blocking buffer ( $1 \%$ bovine plasma albumin and Tris-buffered saline containing $0.1 \%$ Tween-20 (TBST)) for $1 \mathrm{~h}$ at room temperature, the membranes were incubated with rabbit anti-fibrinogen antibodies (Abcam, USA). The membranes were then washed with TBST three times for $5 \mathrm{~min}$ each and probed with alkaline phosphatase-labelled goat anti-rabbit antibodies at room temperature. After washing the membranes as described above, specific bands were visualised using the ECL plus detection system (GE Healthcare Life Sciences) and relative abundance was evaluated by densitometry. The relative expression level of each protein was normalised to a reference protein ( $\beta$-actin).

\section{Results}

Differentially expressed proteins identified by 2-DE and clustering analyses. Clustering analysis identified 63 differentially expressed spots between the two groups (Fig. 1). Out of 33 spots collected for mass spectra, 26 were successfully identified, which included 11 kinds of differentially expressed proteins (Table 1).

The expression levels of four proteins were upregulated in group $\mathrm{T}$ as compared with group $\mathrm{C}$, including chain $\mathrm{A}$, the complex structure of the map kinase P38SB216995 (MAPKp38), haptoglobin (Hp), Ig heavy chain precursor (Ig), and the crystal structure of modified bovine fibrinogen $(\mathrm{Fb})$. The expression levels of seven proteins were down-regulated, including albumin (ALB), apolipoprotein A-I (AppA), complement factor $\mathrm{B}$ precursor (CBp), egg albumin (EALB), fibroin light chain (Fn), protein HP-25 homolog 1 precursor (HP25), and retinol-binding protein 4 (RBP4). MS and 2-DE gel results of the spots 2108 and 6804 are shown in Fig. 2.

Bioinformatic analysis. The results of bioinformatic analysis are shown in Fig. 3. Four out of 11 differentially expressed proteins were not mapped to the database of Biological Process (BP). $\mathrm{BP}$ analysis of seven differentially proteins were classified as external stimulus (GO:0009605), response to nutrient levels (GO:0031667), response to extracellular stimulus (GO:0009991), regulation of immune response (GO:0050776), response to stimulus (GO:0050896), regulation of immune system process (GO:0002682), and regulation of response to stimulus (GO:0048583). Also, three out of 11 differentially expressed proteins were not mapped to the database of Molecular Function (MF). The MF results identified six terms: response to external stimulus (GO:0009605), response to nutrient levels (GO:0031667), response to extracellular stimulus (GO:0009991), regulation of immune response (GO:0050776), response to stimulus (GO:0050896), regulation of immune system process (GO:0002682), and regulation of response to stimulus (GO:0048583).

Forty terms were matched by KEGG pathway analysis. By filtrate, four of these terms were potentially related with footrot in the cows, including complement and coagulation cascades (hsa04610), inflammatory mediator regulation of transient receptor potential (TRP) channels (hsa04750), MAPK signalling pathway (hsa04010), and Staphylococcus aureus infection (hsa05150).

Western blotting analysis. Western blotting was performed to verify the results of 2-DE analysis. Fibrinogen was selected for Western blotting with normalisation to $\beta$-actin as a reference protein. The SDS page image of fibrinogen and $\beta$-actin is presented in the top part of Fig. 4, whereas the analysis of grey values is shown in the bottom part of Fig. 4. Statistical analysis using IBM SPSS software (V19.0; IBM-SPSS, Inc., USA) revealed significant differences in the grey values of fibrinogen between the two groups $(\mathrm{P}=0.001,<0.01 ; t$ test; $\mathrm{P}$ value of $\beta$-actin $=0.603)$.

Table 1. The list of 11 typical differentially expressed proteins

\begin{tabular}{|c|c|c|c|c|}
\hline Spots No. & GI No. & Name of proteins & Fold change & $\mathrm{P}$ value \\
\hline 7202 & gi|1351907 & Albumin & 0.50 & 0.03 \\
\hline 5007 & gi|245563 & Apolipoprotein A-I & 0.11 & 0.01 \\
\hline 2108 & gi|5821844 & $\begin{array}{l}\text { Chain A, the complex structure of the map kinase } \\
\text { P38SB216995 }\end{array}$ & 106.64 & 0.03 \\
\hline 6804 & gi|95147674 & Complement factor B precursor & 0.13 & 0.01 \\
\hline 6007 & gi|129293 & Egg albumin & 0.15 & 0.01 \\
\hline 8004 & gi|119850 & Fibroin light chain & 0.12 & 0.02 \\
\hline 6107 & gi|94966763 & Haptoglobin & 8.65 & 0.04 \\
\hline 3115 & gi 108750 & Ig heavy chain precursor & 24.83 & 0.01 \\
\hline 2008 & gi|114050753 & Protein HP-25 homolog 1 precursor & 0.55 & 0.02 \\
\hline 5009 & gi|132403 & Retinol-binding protein 4 & 0.18 & 0.02 \\
\hline 8109 & gi|6980814 & Crystal structure of modified bovine fibrinogen & 20.52 & 0.01 \\
\hline
\end{tabular}




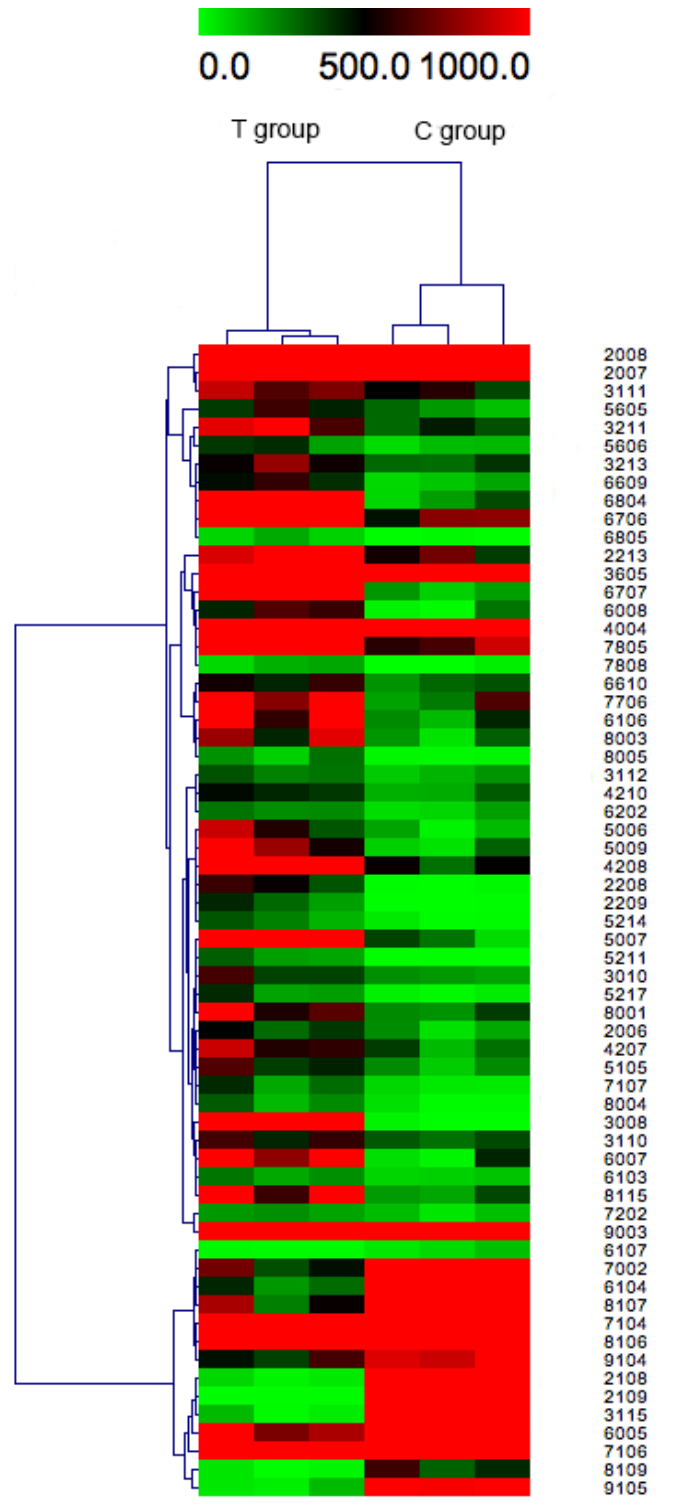

Fig. 1. A heat map of differentially expressed proteins generated using $\mathrm{MeV}$ software
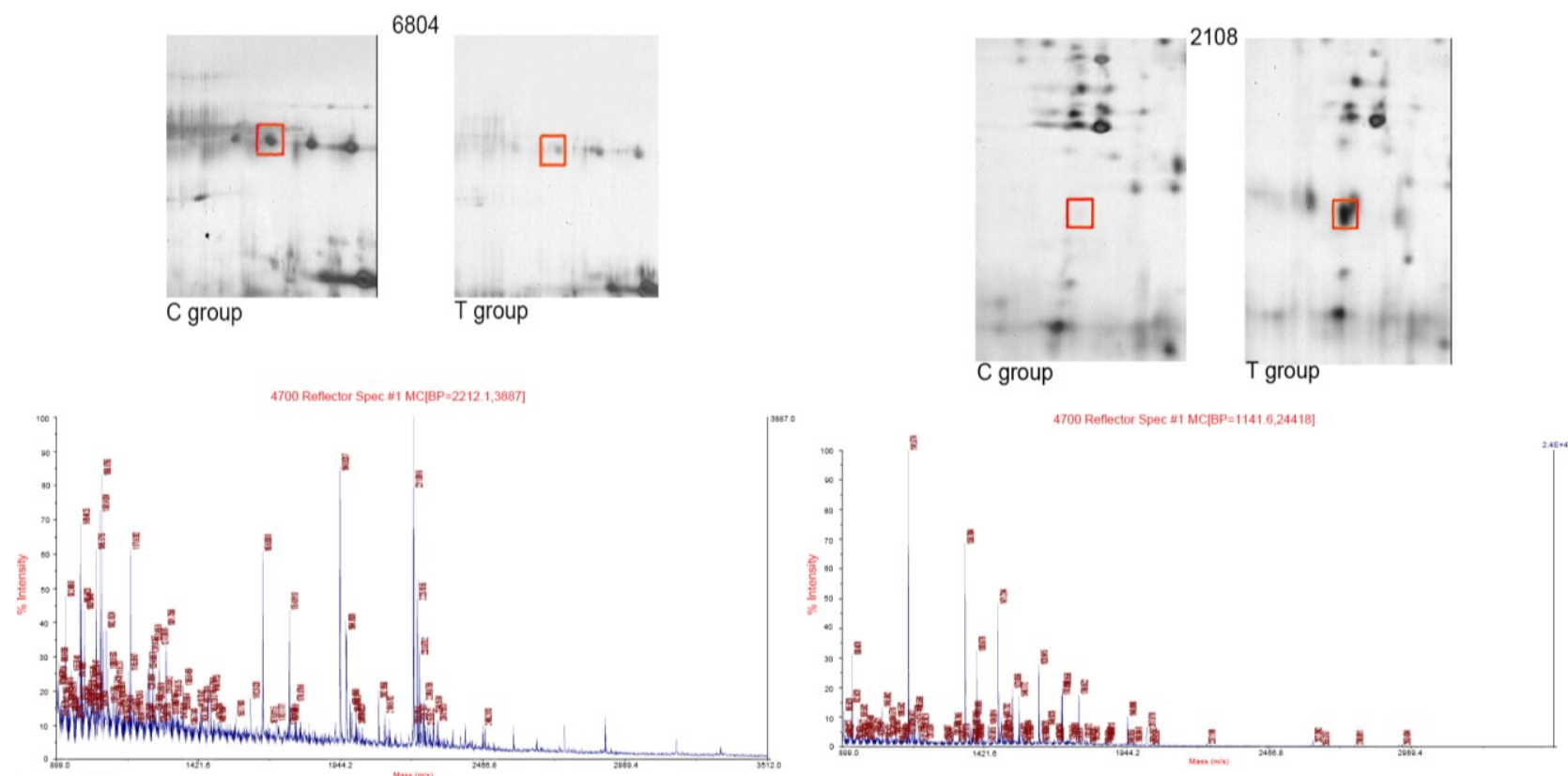

Fig. 2. Above, a representative tandem gel image of spots 6804 and 2108 is shown; below are the mass spectra of the two spots 

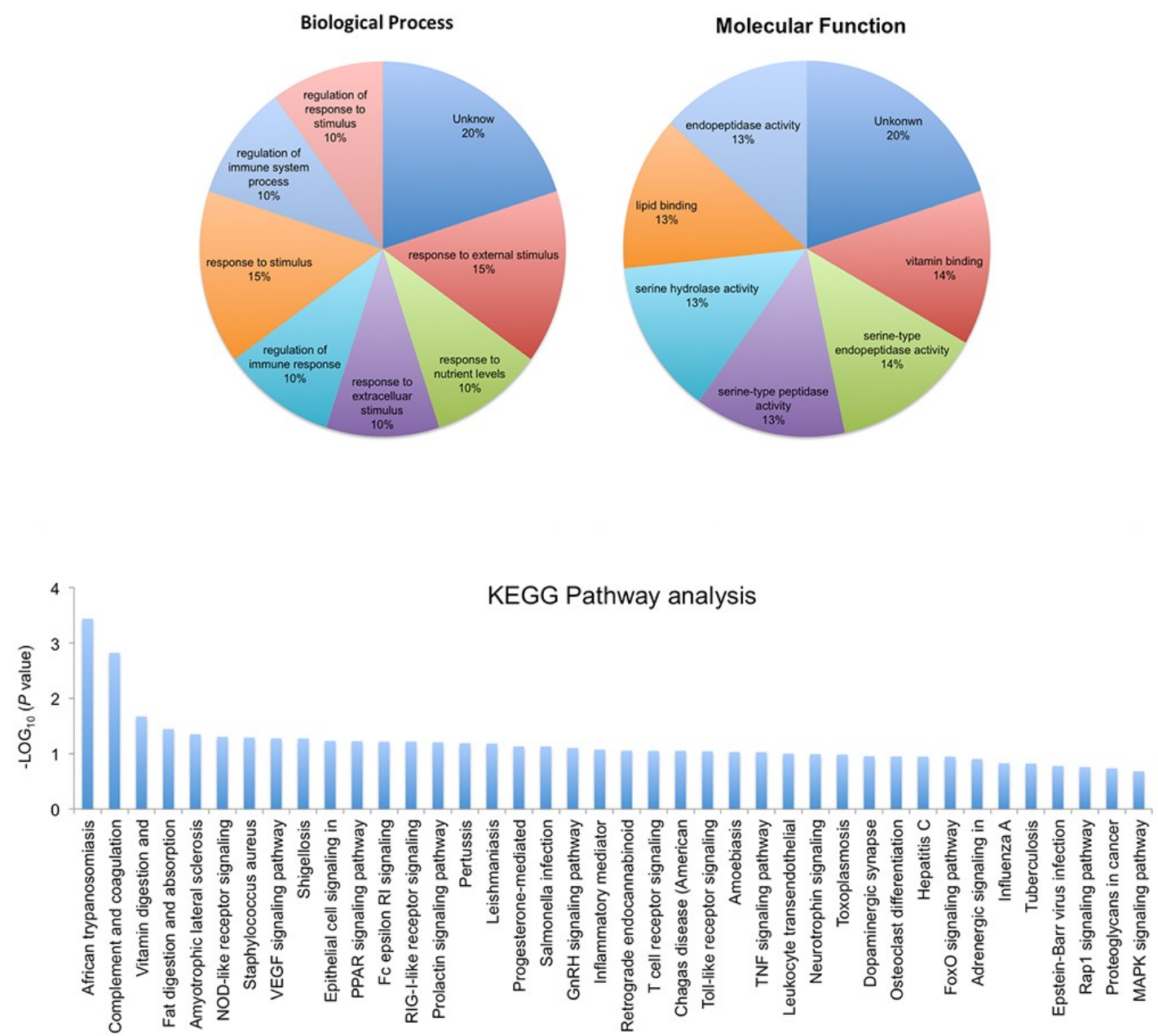

Fig. 3. The results of bioinformatic analysis. Top: the enriched BP and MF according to DAVID Bioinformatics Resources based on the 11 differentially expressed proteins identified in dairy cows with footrot. Bottom: the results of KEGG pathway analysis (http://www.genome.jp/kegg/pathway.html)
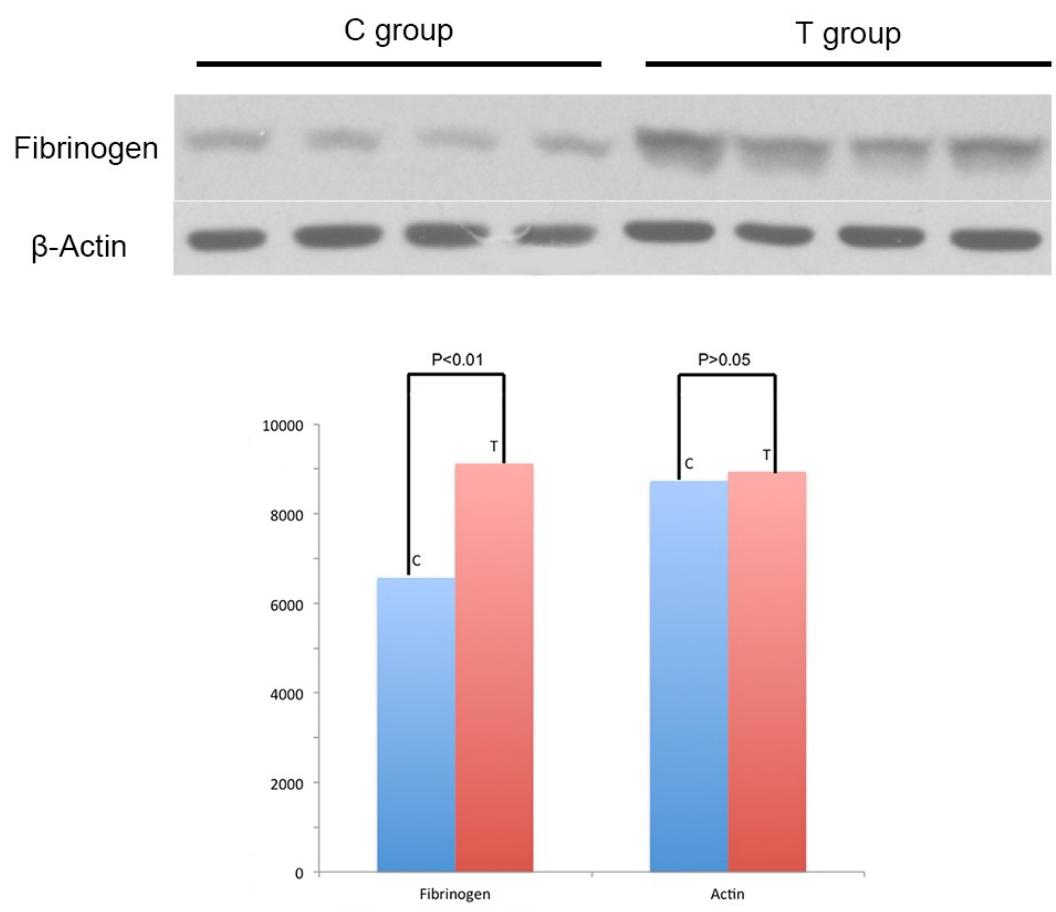

Fig. 4. Fibrinogen and $\beta$-actin validated by Western blotting analysis. Top: four subsets of four $\mathrm{C}$ and four $\mathrm{T}$ groups were analysed by Western blotting for fibrinogen and $\beta$-actin. Bottom: the expression patterns of the two proteins in the entire set of cows 


\section{Discussion}

As evidenced by the completion of genome sequencing of many species, proteomics technology has become an important tool to elucidate gene function and physiological mechanisms. In this study, differential expression of some important proteins, including MAP kinases, fibrinogen, and $\mathrm{Hp}$, among others, was identified by proteomics technology.

The mitogen-activated protein kinase (MAPK) is a serine/threonine/tyrosine-specific protein kinase belonging to the CMGC (CDK/MAPK/G3K3/CLK) kinase group, which is involved in the processes of cell proliferation regulation, gene expression, differentiation, mitosis, cell survival, and apoptosis (10, 15). KEGG pathway analysis showed that MAPKp38 was involved in the "inflammatory mediator regulation of TRP channels" and "MAPK signalling pathway". As is known, footrot in dairy cows is characterised by a series of acute inflammation reactions following bacterial infection through injured skin, which activates the "inflammatory mediator regulation of TRP channels" pathway. MAPK activity and immune inflammation were closely related and other studies have reported that MAPKp38 can induce the upregulation of inflammation cytokines and adhesion proteins, which are closely associated with inflammation factors, such as vascular cell adhesion molecule-1 (13). In this study, MAPKp38 was significantly up-regulated in the footrot group, and was maintained at a relatively low level in the healthy group. Based on these findings, we speculated that the inflammation response is triggered by footrot. In the inflammation response process, expression of MAPKp38, which plays an important exacerbating role in the "MAPK signalling pathway" was up-regulated.

Fibrinogen is an important clotting factor during the acute response phase to infectious diseases and noninfectious sterile inflammation processes, and is associated with the stress response (21). Many studies have shown that this protein can also serve as a sensitive indicator to evaluate treatment response and as a marker of inflammation $(8,9)$. Footrot is an acute suppurative inflammation response of interdigital skin. In this study, Western blotting analysis showed that fibrinogen expression was up-regulated in the footrot group. Fibrinogen was also identified as an inflammation biomarker, suggesting that fibrinogen may contribute to the inflammation underlying the development and progression of footrot.

Haptoglobin ( $\mathrm{Hp})$ is an acute phase protein (APP), which is ubiquitous in the blood and other body fluids of humans, mammals, and other vertebrates, plays a very important role against infection, repair of tissue damage, and maintenance of a stable internal environment. Serum Hp levels quickly increase in states of infection due to the pathological state, inflammation, and stress $(1,11,22)$. The acute phase response is an early host response induced by injury, inflammation, and infection, thus monitoring serum APPs can objectively reflect healthy status $(3,14)$. Eckersall (5) reported that serum Hp levels can quickly increase by 100 -fold in the acute phase of cow mastitis. Likewise, Hp expression in this study was significantly up-regulated in the footrot group compared with the healthy cows. These results indicate that $\mathrm{Hp}$ is a potential biomarker for diagnosis of footrot in dairy cows.

To the best of our knowledge, this is the first report of comparative serum proteomic analysis of dairy cattle affected by footrot using a 2-DE-MS proteomic technique, which is a highly efficient method to identify differentially expressed serum proteins. In this study, 11 different serum proteins identified by 2-DE-MS were differentially expressed between serum samples from health dairy cattle and those with footrot. The identification of differentially expressed proteins that may promote the development of footrot in dairy cattle is expected to further aid in the development of strategies to control and prevent this disease. The differentially expressed serum proteins identified in this study will enrich our understanding of relevant mechanisms in the progression of footrot and also provide important biomarkers for diagnosis of this disease. Nevertheless, a number of differentially expressed proteins between the two groups revealed in this study indicate the need for further studies as well.

Conflict of Interests Statement: The authors declare that there is no conflict of interests regarding the publication of this article.

Financial Disclosure Statement: This research was supported by grants from the National Key Technology R\&D Programme (grant no. 2012BAD12B05-2), the National Key Technology R\&D Programme (grant no. 2013BAD21B01), and the Natural Science Foundation of Heilongjiang Province of China (grant no. C201229).

Animal Rights Statement: The study was performed in accordance with the Ethical Committee for Animal Experiments (Northeast Agricultural University, Harbin, China) and in accordance with the policies of the Institutional Animal Care and Use Committee of Heilongjiang Bayi Agricultural University (Daqing, People's Republic of China).

\section{References}

1. Baumann H., Held W.A., Berger F.G.: The acute phase response of mouse liver, genetic analysis of the major acute phase reactants. J Biol Chem 1984, 259, 566-573.

2. Bradford M.M.: A rapid and sensitive method for the quantitation of microgram quantities of protein utilizing the principle of protein-dye binding. Anal Biochem 1976, 72, 248-254

3. Chen H.H., Lin J.H., Fung H.P., Ho L.L., Yang P.C., Lee W.C., Lee Y.P., Chu R.M.: Serum acute phase proteins and swine health status. Can J Vet Res 2003, 67, 283-290. 
4. Dong S.W., Zhang S.D., Wang D.S., Wang H., Shang X.F., Yan P., Yan Z.T., Yang Z.Q.: Comparative proteomics analysis provide novel insight into laminitis in Chinese Holstein cows. BMC Vet Res 2015, 11, 161.

5. Eckersall P.D.: Recent advances and future prospects for the use of acute phase protein as markers of disease in animals. Rev Med Vet Toulouse 2000, 151, 577-584.

6. Guo D.H., Sun D.B., Wu R., Yang H.M., Zheng J.S., Fan C.L., Sun B., Wang J.F.: An indirect ELISA for serodiagnosis of cattle footrot caused by Fusobacterium necrophorum. Anaerobe 2010, $16,317-320$.

7. Hernandez J., Shearer J.K., Webb D.W.: Effect of lameness on the calving-to-conception interval in dairy cows. J Am Vet Med Assoc 2001, 218: 1611-1614.

8. Ingegnoli F., Fantini F., Favalli E.G., Soldi A., Griffini S., Galbiati V., Meroni P.L., Cugno M.: Inflammatory and prothrombotic biomarkers in patients with rheumatoid arthritis: effects of tumor necrosis factor-alpha blockade. J Autoimmun 2008, 31, 175-179.

9. Jin T., Bokarewa M., Amu S., Tarkowski A.: Impact of shortterm therapies with biologics on prothrombotic biomarkers in rheumatoid arthritis. Clin Exp Rheumatol 2009, 27, 491-494.

10. Johnson G.L., Lapadat R.: Mitogen-activated protein kinase pathways mediated by ERK, JNK, and p38 protein kinases. Science 2002, 298, 1911-1912.

11. Langlois M.R., Delanghe J.R.: Biological and clinical significance of haptoglobin polymorphism in humans. Clin Chem 1996, 42, 1589-1600.

12. Magdeldin S., Enany S., Yoshida Y., Xu B., Zhang Y., Zureena Z., Lokamani I., Yaoita E., Yamamoto T.: Basics and recent advances of two dimensional - polyacrylamide gel electrophoresis. Clin Proteomics 2014, 4, 3665-3685.

13. Ono K., Han J.: The p38 signal transduction pathway: activation and function. Cell Signal 2000, 12, 1-13.
14. Parra M.D., Fuentes P., Tecles F., Martínez-Subiela S., Martínez J.S., Muñoz A., Cerón J.J.: Porcine acute phase protein concentrations in different diseases in field condition. J Vet Med 2006, 53, 488-493.

15. Robinson M.J., Cobb M.H.: Mitogen-activated protein kinase pathways. Curr Opin Cell Biol 1997, 9, 180-186.

16. Shevchenko A., Wilm M., Vorm O., Jensen O.N., Podtelejnikov A.V., Neubauer G., Shevchenko A., Mortensen P., Mann M.: A strategy for identifying gel-separated proteins in sequenxe databases by MS alone. Biochem Soc Trans 1996, 24, 893-896.

17. Sun D., Wu R., Li G., Zheng J., Liu X., Lin Y., Guo D.: Identification of three immunodominant regions on leukotoxin protein of Fusobacterium necrophorum. Vet Res Commun 2009, 33, 749-755.

18. Sun D., Zhang H., Guo D., Sun A., Wang H.: Shotgun proteomic analysis of plasma from dairy cattle suffering from footrot: characterization of potential disease-associated factors. Plos One 2013, 8, 55973

19. Tølbøll T.H., Danscher A.M., Andersen P.H., Codrea M.C., Bendixen E.: Proteomics: a new tool in bovine claw disease research. Vet J 2012, 193, 694-700.

20. Warnick L.D., Janssen D., Guard C.L., Gröhn Y.T.: The effect of lameness on milk production in dairy cows. J Dairy Sci 2001, 84, 1988-1997.

21. Weisel J.W., Stauffacher C.V., Bullitt E., Cohen C.: A model for fibrinogen: domains and sequence. Science 1985, 230, 1388-1391.

22. Yang F., Friedrichs W.E., Navarijo-Ashbaugh A.L., deGraffenried L.A., Bowman B.H., Coalson J.J.: Cell typespecific and inflammatory-induced expression of haptoglobin gene in lung. Lab Invest 1995, 73, 433-440.

23. Zhou H., Bennett G., Hickford J.G.: Variation in Fusobacterium necrophorum strains present on the hooves of footrot infected sheep, goats and cattle. Vet Microbiol 2009, 135, 363-367. 